\title{
Portability of Scientific Manuscripts and Reviewers' Comments
}

\author{
Shoban Haridass ${ }^{1}$ Shyamkumar N. Keshava \\ ${ }^{1}$ Department of Interventional Radiology, Division of Clinical \\ Radiology, Christian Medical College, Vellore, Tamil Nadu, India \\ ${ }^{2}$ Division of Interventional Radiology, Department of Radiology, \\ Massachusetts General Hospital, Boston, Massachusetts, \\ United States
}

J Clin Interv Radiol ISVIR 2021;6:1-2.

Peer-reviewing is an essential and indispensable step in the process of scientific publication. It helps ensure good quality of manuscripts before publication. ${ }^{1}$ However, not all rejected articles are poor in quality and reasons for rejection may be multifactorial. ${ }^{2}$ A good scientific manuscript may be rejected for simple reasons such as a journal's high rejection rate for a particular type of scientific studies, mismatch between the content, and the potential interest of its readers as assessed by the editorial board or because the information has already been adequately published in that particular journal. Conventionally, once the article is rejected, authors search to find an alternative or a more suitable journal to publish their work. This delays publishing of the manuscript and would potentially reduce the value and relevance of the content. Options to overcome this delay are explored in this editorial.

"Portability of manuscript" is an optional service provided by a few publishers to cater to a rejected manuscript. ${ }^{3}$ A consultant would briefly analyze the contents, reasons for rejection, and may suggest possible alternative journal options within their publication group. The authors have the option to choose the suggestions and confirm the submission to the new journal.

In a portable peer-review system, the journal that rejected a manuscript provides an option of sharing their reviewers' comments on resubmission of the manuscript to an alternative journal not belonging to same publishing group. This helps in saving time, effort and avoids duplication of work. ${ }^{4}$ Sometimes the reasons for manuscript rejection by one particular journal may not be applicable to the next journal. This option of portable peer review may be opted for by authors based on reasons for manuscript rejection and the scope of the alternative journal. If needed, the editor may add new reviewer(s) following the transfer.

\begin{abstract}
Address for correspondence Shyamkumar N. Keshava, DMRD, DNB, FRCR, FRANZCR, Department of Interventional Radiology, Division of Clinical Radiology, Christian Medical College, Ida Scudder Road, Vellore 632004, Tamil Nadu, India (e-mail: shyamkumar.n.keshava@gmail.com).
\end{abstract}

In cascade or waterfall peer-review system, the reviewers' comments are shared during resubmission of the manuscript to a different, more suitable journal belonging to same publishing group. The transferred journal is usually of a lower reputation or has a lower impact factor. ${ }^{4} \mathrm{~A}$ free consultation by the publisher is often provided to the authors. The publisher has the advantage of retaining good content within their pool of publications. Considering this option, many publishers maintain a uniform manuscript structuring, and formatting across their journals.

The publisher should have an adequate number of journals with overlapping or at least, partially overlapping interests. For example, a manuscript on gastrointestinal radiology may be of common interest to journals of radiology, interventional radiology, gastroradiology, and clinical gastroenterology. A broad specialty journal should have specific subsections for easy identification and navigation through the journal. Careful selection of keywords also will be useful. A good rapport and understanding among editorial boards would facilitate a smooth exchange process.

Another strategic advantage of cascade peer-review system is retaining the first submission date while resubmitting to another journal within the publishing group. This aids in retaining seniority while claiming credits to their ideas.

In this digital era, we should be able to maximize available opportunities for authors, publishers, and readers. Everyone's time and effort should be valued. Perhaps, portability of the manuscripts would enhance the publication possibility of good material as some authors would "give up" especially if they under-rate their own work. In addition, this would reduce review junk. ${ }^{5}$ Overall, this results in a win-win situation.
Dol https://doi.org/ $10.1055 / \mathrm{s}-0041-1741366$ ISSN 2457-0214
(C) 2022. Indian Society of Vascular and Interventional Radiology.

This is an open access article published by Thieme under the terms of the Creative Commons Attribution-NonDerivative-NonCommercial-License, permitting copying and reproduction so long as the original work is given appropriate credit. Contents may not be used for commercial purposes, or adapted, remixed, transformed or built upon. (https://creativecommons.org/licenses/by-nc-nd/4.0/).

Thieme Medical and Scientific Publishers Pvt. Ltd. A-12, 2nd Floor, Sector 2, Noida-201301 UP, India 


\section{Conflict of Interest}

None declared.

\section{References}

1 Kelly J, Sadeghieh T, Adeli K. Peer review in scientific publications: benefits, critiques, \& a survival guide. EJIFCC 2014;25(3):227-243
2 Ali J. Manuscript rejection: causes and remedies. J Young Pharm 2010;2(1):3-6

3 Lemberger T. Partnering with life science alliance. Mol Syst Biol 2018;14(4):e8327

4 Kovanis M, Trinquart L, Ravaud P, Porcher R. Evaluating alternative systems of peer review: a large-scale agent-based modelling approach to scientific publication. Scientometrics 2017;113(1):651-671

5 Bell GP, Kvajo M. Tackling waste in publishing through portable peer review. BMC Biol 2018;16(1):146 